\title{
Bovine fetal mesenchymal stem cells exert antiproliferative effect against mastitis causing pathogen Staphylococcus aureus
}

Berly Cahuascanco ${ }^{1}$, Javiera Bahamonde ${ }^{1,5,6}$, Olger Huaman ${ }^{1}$, Miguel Jervis ${ }^{1}$, Jahaira Cortez ${ }^{1}$, Jaime Palomino ${ }^{1}$, Alejandro Escobar ${ }^{2}$, Patricio Retamal ${ }^{3}$, Cristian G. Torres ${ }^{4}$ and Oscar Alejandro Peralta ${ }^{1,5^{*}}$ (1)

\begin{abstract}
Staphylococcus aureus is the most commonly isolated pathogen from clinical bovine mastitis samples and a difficult pathogen to combat. Mesenchymal stem cells (MSC) are multipotent progenitor cells equipped with a variety of factors that inhibit bacterial growth. The aim of the present study was to evaluate the in vitro antibacterial potential against $S$. aureus of conditioned medium (CM) from MSC derived from fetal bovine bone marrow (BM-MSC) and adipose tissue (AT-MSC). BM-MSC, AT-MSC and fetal fibroblasts (FB) cultures were activated by infection with S. aureus. Bacterial growth was evaluated in presence of $C M$, concentrated $C M(C C M)$, activated CM (ACM) and concentrated ACM (CACM) from BM-MSC, AT-MSC and FB. Gene expression of $\beta$-defensin 4A (bBD-4A), NK-lysine 1 (NK1), cathelici$\operatorname{din} 2$ (CATHL2), hepcidin (HEP) and indoleamine 2,3 dioxygenase (IDO) and protein expression of bBD-4A were determined in activated and non-activated cells. The majority of BM-MSC and AT-MSC expressed CD73, Oct4 and Nanog, and were negative for CD34. Growth of S. aureus decreased when it was exposed to CM from BM-MSC, AT-MSC and FB. Moreover, growth of S. aureus in CCM, ACM and CACM was lower compared to controls of CM from BM-MSC and AT-MSC. Activated AT-MSC increased mRNA levels of bBD4A and NK1, and protein levels of bBD4A in CM. Thus, CM from fetal bovine BM-MSC and AT-MSC has the capacity to reduce in average $\sim 30 \%$ of S. aureus relative growth under in vitro conditions. The in vitro antibacterial effect of fetal bovine MSC may be mediated by bBD4A and NK1 activity.
\end{abstract}

\section{Introduction}

Mesenchymal stem cells (MSC) are multipotent progenitor cells with ability to self-renew and differentiate into tissues of mesodermal origin including osteoblasts, adipocytes, chondrocytes and myocytes [1]. Based on the ability to adhere to plastic when plated in monolayer culture, MSC can be isolated from several tissue sources including bone marrow (BM) and adipose tissue (AT) [2]. Plastic adherence under standard culture conditions is the first criteria established by the international society for cellular therapy (ISCT) for defining human MSC [3]. Additional criteria include trilineage differentiation potential and expression of MSC surface antigens

\footnotetext{
*Correspondence: operalta@uchile.cl

1 Department of Animal Production Science, Faculty of Veterinary

Medicine, University of Chile, 8820808 Santiago, Chile

Full list of author information is available at the end of the article
}

markers CD105 (endoglin), CD73 (ecto-5'-nucleotidase) and CD90 (Thy-1), and lack of expression of hematopoietic markers CD45 (protein tyrosine phosphatase, receptor type, C), CD34 (CD34 molecule) and CD14 (CD14 molecule). The trophic capacity of MSC from adult tissues represents a promising therapeutic strategy for the treatment of a wide range of pathologies in human and veterinary medicine. Thus, there is high scientific interest in better understanding the mechanism underlying these potential therapeutic effects.

Numerous studies have reported that MSC exert reparative functions through paracrine activity including immunomodulatory effects mediated by dendritic and $\mathrm{B}$ and $\mathrm{T}$ cells, and trophic functions involving antiapoptotic, proangiogenic and mitogenic factors [4]. Moreover, a large body of evidence indicates that MSC enhance bacterial clearance through the expression of antibacterial peptides (AP) including cathelicidin (CATHL2),

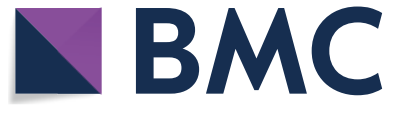

(c) The Author(s) 2019. This article is distributed under the terms of the Creative Commons Attribution 4.0 International License (http://creativecommons.org/licenses/by/4.0/), which permits unrestricted use, distribution, and reproduction in any medium, provided you give appropriate credit to the original author(s) and the source, provide a link to the Creative Commons license, and indicate if changes were made. The Creative Commons Public Domain Dedication waiver (http://creativecommons.org/ publicdomain/zero/1.0/) applies to the data made available in this article, unless otherwise stated. 
indolamine 2,3-dioxygenase (IDO) and hepcidin (HEP) [5-7]. CATHL2 LL-37 from human MSC is a membrane pore-forming AP that has been shown to inhibit in vitro bacterial growth of Escherichia coli, Pseudomona aeruginosa, and Staphylococcus aureus [5]. IDO is a key mediator of immune tolerance whose activity as a catabolic enzyme can deplete tryptophan in MSC cultures, thereby hindering growth of S. aureus, Staphylococcus epidermidis, Enterococcus faecium and E. coli [6]. Menstrual fluid derived MSC exert an important antimicrobial effect against fecal bacteria mediated by HEP [7]. HEP acts as an iron regulatory hormone that may reduce iron levels and limits its availability to microorganisms [8]. These studies suggest that MSC are equipped with a variety of factors that may be useful to fight infection in a diversity of in vivo settings.

Inflammation of the mammary gland or mastitis, manly as a consequence of infectious agents, is the most prevalent and costly disease for dairy herds worldwide. It has been reported that $S$. aureus is the most commonly isolated pathogen from clinical mastitis samples and the second most commonly isolated pathogen in subclinical samples [9]. S. aureus can survive in neutrophils, invade into mammary epithelial cells, form micro abscesses, and promote biofilm formation [10]. Despite in vitro antimicrobial susceptibility of $S$. aureus remains relatively high, pathogen factors make $S$. aureus a difficult pathogen to combat due to the restriction of their contact with antibiotics [11]. Consequently, percentages of cure in mastitis caused by $S$. aureus using currently approved antibiotics (e.g., pirlimycin) range only between 10 and 30\% [12]. Considering that therapies available for the treatment of mastitis caused by $S$. aureus remain suboptimal, culling infected cows is a commonly used strategy to reduce new intramammary infection in infected herds.

In addition to its negative economic impact, mastitis has also been declared as the main disease threating animal welfare [13]. Bovine mastitis also affects public health by altering physical and microbiological properties of milk and increasing content of residues. Currently, treatment of mastitis is based on the use of antibiotics, aiming at controlling bacterial infection of the mammary gland. Nevertheless, this approach is not always effective and the inadequate use of antibiotics may result in bacterial resistance. Penicillin resistance is probably the most well-known antibiotic resistance of $S$. aureus with levels that differ considerably between countries ranging from 20 to $30 \%$ to more than $85 \%$ [14]. In addition, antibiotic treatment does not promote the regeneration of the mammary gland tissue, which is a crucial effect for future milk production. Thus, development of new therapeutic alternatives for the effective control and treatment of bovine mastitis is important aspect for veterinary medicine. In the present study, we aimed at evaluating the in vitro antibacterial potential against $S$. aureus of conditioned medium (CM) derived from MSC isolated from fetal bovine bone marrow (BM-MSC) and adipose tissue (AT-MSC).

\section{Materials and methods \\ Isolation and culture of bovine fetal BM-MSC, AT-MSC and fibroblasts}

BM-MSC were harvested following a previously reported protocol that ensured establishment of MSC cultures that fulfill the minimal criteria for definition of MSCs [15, $16]$. $\mathrm{BM}$ was aspirated from male bovine fetuses $(n=9$; 7-8 months of gestation) collected at a local abattoir. The BM was drawn from femoral cavity into syringes containing high glucose $(4.5 \mathrm{~g} / \mathrm{L})$ Dulbecco's Modified Eagle Medium (DMEM, Gibco, Grand Islands, NY, USA) supplemented with $100 \mathrm{IU} / \mathrm{mL}$ penicillin, $100 \mu \mathrm{g} / \mathrm{mL}$ streptomycin and $2.5 \mu \mathrm{g} / \mathrm{mL}$ amphotericin B (Hyclone, Thermo Fisher Scientific, UT, USA). BM samples from three fetuses were pooled and washed twice with phosphatebuffered saline (PBS) and twice with DMEM. AT-MSC were harvested from fetal abdominal omentum from the same fetuses used for BM-MSC isolation. Approximately $10 \mathrm{~g}$ of AT were isolated under aseptic conditions and deposited in PBS supplemented with $100 \mathrm{IU} / \mathrm{mL}$ penicillin, $100 \mu \mathrm{g} / \mathrm{mL}$ streptomycin and $2.5 \mu \mathrm{g} / \mathrm{mL}$ amphotericin B (Hyclone). AT samples from three fetuses were pooled and washed twice with phosphate-buffered saline (PBS; Hyclone) and twice with DMEM. Then, AT was digested in $0.5 \%$ collagenase I (Sigma-Aldrich, St. Louis MO, USA) $(1 \mathrm{~mL} / \mathrm{g}$ of AT) for $45 \mathrm{~min}$. Collagenase I activity was neutralized with DMEM supplemented with $10 \%$ fetal bovine serum (FBS; Gibco), $100 \mathrm{IU} / \mathrm{mL}$ penicillin, $100 \mu \mathrm{g} / \mathrm{mL}$ streptomycin and $2.5 \mu \mathrm{g} / \mathrm{mL}$ amphotericin B (expansion medium). The disrupted tissue was filtered through $40 \mu \mathrm{m}$ pores and subsequently centrifuged at $400 \times g$ for $5 \mathrm{~min}$. The cell pellet was washed once in DMEM, suspended in expansion medium and plated.

Fetal fibroblasts (FB) were used as negative controls and were harvested from epithelial tissue extracted from the muzzle of the same fetuses used for BM-MSC and AT-MSC isolation. Tissue from three fetuses was isolated under aseptic conditions, pooled and washed in PBS supplemented with $100 \mathrm{IU} / \mathrm{mL}$ penicillin, $100 \mu \mathrm{g} /$ $\mathrm{mL}$ streptomycin and $2.5 \mu \mathrm{g} / \mathrm{mL}$ amphotericin B. Tissue was washed in PBS and digested in $0.5 \%$ collagenase I at $37{ }^{\circ} \mathrm{C}$ for $90 \mathrm{~min}$. Collagenase I activity was neutralized with expansion medium. The disrupted tissue was filtered through $40 \mu \mathrm{m}$ pores and subsequently centrifuged at $400 \times g$ for $5 \mathrm{~min}$. The cell pellet was washed once with DMEM, suspended in expansion medium and plated. BM-MSC, AT-MSC or FB were plated in expansion 
media and incubated at $38.5{ }^{\circ} \mathrm{C}$ in a humidified atmosphere containing $5 \% \mathrm{CO}_{2}$. After 2 days, non-adherent cells were removed by changing the culture medium. Following the initial 2 days, the medium was changed every 2 to 3 days. After 3 to 4 passages, cells were gently harvested when $90 \%$ confluent using $0.05 \%$ trypsin in $0.02 \%$ EDTA. Cultures of both MSC lines were characterized by quantification of CD73, CD34, Oct-4 and Nanog expression. Following determination of cell viability, cells were used to initiate experiments.

\section{Flow cytometry analysis}

Determination of cell population positive for CD73, CD34, Oct4 and Nanog was estimated using fluorescence-activated cell sorter (FACS) analysis. Approximately $1-3 \times 10^{6}$ cells obtained from BM-MSC and AT-MSC cultures were detached after incubation in EDTA for $10-20 \mathrm{~min}$ at $38.5{ }^{\circ} \mathrm{C}$ and centrifuged at $400 \times g$ for $5 \mathrm{~min}$. Cells were then fixed with $4 \%$ paraformaldehyde in PBS for $10-15$ min at $4{ }^{\circ} \mathrm{C}$, washed with PBS and stored at $4{ }^{\circ} \mathrm{C}$ overnight. Samples were centrifuged at $1110 \times g$ for $5 \mathrm{~min}$, resuspended in a solution of $1 \%$ Triton X100 in PBS, incubated during 15 min at room temperature, centrifuged at $1110 \times g$ for $5 \mathrm{~min}$, and then resuspended in $0.1 \%$ tween in PBS for washing. Antigens were blocked using a solution of $3 \%$ bovine serum albumin (BSA) with $1.5 \mathrm{mg} / \mathrm{mL}$ of glycine during $1 \mathrm{~h}$ at room temperature and then were washed with PBS and centrifuged $1110 \times g$ for $5 \mathrm{~min}$. Cells were incubated overnight in goat polyclonal anti-CD73, anti-CD34, antiOct4 or anti-Nanog antibodies (Cat. \#sc-14682; sc-7045; sc-8628 and sc-30331; Santa Cruz Biotechnology, Santa Cruz, CA, USA) diluted (1:200) in 3\% BSA in PBS. Cells were washed thrice in $0.1 \%$ tween in PBS, centrifuged at $1110 \times g$ for $5 \mathrm{~min}$ and incubated in a solution of rabbit anti-goat IgG conjugated with Alexa Fluor 488 (Cat. \#A11078; Thermo Fisher Scientific, Rockford, IL, USA)

Table 1 Characterization of strain SAU-1S of Staphylococcus aureus used for determination of the antibacterial potential of bovine fetal BM-MSC and AT-MSC

\begin{tabular}{ll}
\hline Strain & SAU-1S \\
\hline $\begin{array}{l}\text { Biochemical tests } \\
\text { Source }\end{array}$ & $\begin{array}{l}\text { Catalase and coagulase positive } \\
\text { Isolated from clinical bovine mastitis case follow- } \\
\text { ing recommendations of the National Mastitis } \\
\text { Council (NMC) }\end{array}$ \\
$\begin{array}{l}\text { Antimicrobial suscep- } \\
\text { tibility }\end{array}$ & $\begin{array}{l}\text { Empicillin, Cefadroxil, Cephalothin, Ceftiofur, } \\
\text { Penicillin, Tetracycline }\end{array}$ \\
Virulence factors & $\begin{array}{l}\text { Adhesion Factor A and B, elastin-binding protein, } \\
\text { bone sialoprotein-binding protein, protein A, } \\
\text { hemolysin and intracellular adhesion operon A } \\
\text { and D, moderate capacity to form biofilm }\end{array}$ \\
\hline
\end{tabular}

diluted (1:1000) in 3\% BSA during $1 \mathrm{~h}$ at room temperature. Then cells were washed thrice in $0.1 \%$ tween and then incubated with $3 \mu \mathrm{L}$ propidium iodide for $5 \mathrm{~min}$ at room temperature. Cells were resuspended in IsoFlow buffer and analyzed (three replicates) using a Gallios Flow Cytometer (Beckman Coulter, Brea, CA, USA) using a 488-nm laser light. The threshold for negative events was set on the first decade of fluorescence level histogram. Negative procedural control corresponded to cells not incubated with antibodies (autofluorescence) and cells incubated only with secondary antibody. Percentage of cells positive for autofluorescence and secondary antibody were subtracted from the percentage of cells positive with primary and secondary antibodies.

\section{Conditioned media collection}

Conditioned media was collected from BM-MSC and AT-MSC and FB derived from the same bovine fetuses. To this end, $6 \times 10^{3}$ cells $/ \mathrm{cm}^{2}$ at passages $3-5$ were seeded in T75 flasks with culture medium until reaching $70-80 \%$ confluency. Then medium was removed, cell monolayers were rinsed twice with PBS and $10 \mathrm{~mL}$ of DMEM (Mediatech, Incorporated, Manassas, VA, USA) were added. Medium was collected $72 \mathrm{~h}$ later, centrifuged twice for 5 min at $400 \times g$ and frozen at $-20^{\circ} \mathrm{C}$ until used for subsequent experiments. Concentrated CM (CCM; tenfold) was obtained by filtration of $\mathrm{CM}$ using Amicon Ultra centrifugal filters (Merck Millipore, Tullagreen, Ireland) with a membrane NMWL of $3 \mathrm{kDa}$ in accordance with the instructions of the manufacturer. Equal volumes of serum-free DMEM but without cells were handled under the same conditions and served as positive controls.

\section{Antimicrobial assay}

Strain SAU-1S of S. aureus was isolated from a clinical bovine mastitis case following the recommendations of the National Mastitis Council (NMC) and then characterized for antibacterial resistance and virulence factors (Table 1). S. aureus SAU-1S colonies were resuspended in $2 \mathrm{~mL}$ of Luria-Bertani (LB) agar (Life Technologies) plates and incubated at $38{ }^{\circ} \mathrm{C}$ in shaking for $24 \mathrm{~h}$. The strain was then seeded on LB agar plates at $4^{\circ}$ for up to 1 month. For each experiment, a colony was picked and resuspended on LB broth and incubated in continuous agitation at $38{ }^{\circ} \mathrm{C}$ until cultures reached the exponential growth phase. The colonies were then washed thrice in PBS (pH 7.4), resuspended (1:100) in CM collected from BM-MSC, AT-MSC and FB, seeded in LB plates and incubated at $38^{\circ}$ for $24 \mathrm{~h}$. For direct inhibition assays, BM-MSC, AT-MSC or FB were cultured in 24-well plates $\left(2 \times 10^{5}\right.$ cells per well $)$ in serum-free DMEM and infected with 300 CFUs of bacteria for $6 \mathrm{~h}$ at $38{ }^{\circ} \mathrm{C}$. Activated $\mathrm{CM}$ (ACM) was collected and the bacterial fraction was 
removed by passing the $\mathrm{CM}$ through a $0.22-\mu \mathrm{m}$ filter. The filtered ACM was centrifuged at $13200 \mathrm{rpm}$ for $10 \mathrm{~min}$. Concentrated ACM (CACM; tenfold) was obtained by filtration of $\mathrm{CM}$ using Amicon Ultra centrifugal filters (Merck Millipore) with a membrane NMWL of $3 \mathrm{kDa}$ in accordance with the instructions of the manufacturer.

In order to determine $S$. aureus growth in $\mathrm{CM}, \mathrm{CCM}$, $\mathrm{ACM}$ and CACM from BM-MSC, AT-MSC and FB, bacterial proliferation was evaluated by CFUs counting at $0,1,2$ and $h$ post-seeding. Bacterial proliferation was expressed as percentage in relation to CFUs at time 0 post-seeding using the following formula: CFUs/ $\mathrm{mL}=($ mean CFUs $\times$ dilution factor $) \times 200$; proliferation rate $=(\mathrm{Tn} \times 100) / \mathrm{T} 0$ where dilution factor is the counting at 1:10 000 dilution; $\mathrm{Tn}$ is the number of CFUs $/ \mathrm{mL}$ at $\mathrm{n} h$ post-inoculation, and $\mathrm{T} 0$ is the number of CFUs $/ \mathrm{mL}$ at $0 \mathrm{~h}$ post-inoculation.

\section{RNA extraction and CDNA synthesis}

Approximately $3 \times 10^{5}$ of activated and non-activated BM-MSC, AT-MSC and FB were collected and immediately fixed in RLT buffer (Qiagen, Incorporated, Valencia, CA, USA) supplemented with $\beta$-mercaptoethanol (Sigma). Total RNA was extracted using GeneJET RNA purification kit (Thermo Fisher Scientific) according to the manufacturer's instructions. Total RNA was eluted in $50 \mu \mathrm{L}$ of RNase free water. The concentration and purity of the RNA in each sample was determined using Qubit RNA assay kit (Life Technologies, Waltham, MA, USA), and genomic DNA was removed using DNase I, RNase-free (Thermo Fisher Scientific). Samples were subjected to reverse transcription using a cDNA synthesis kit (AffinityScript; Agilent Technologies, Santa Clara, CA, USA). The reaction protocol consisted of incubation for $5 \mathrm{~min}$ at $25^{\circ} \mathrm{C}, 15 \mathrm{~min}$ at $42{ }^{\circ} \mathrm{C}, 5 \mathrm{~min}$ at $95{ }^{\circ} \mathrm{C}$, and hold at $4{ }^{\circ} \mathrm{C}$ using a TC1000-G gradient thermocycler (SciLogex, Rocky Hill, CT, USA).

\section{Quantitative-PCR}

Samples were analyzed for genes bBD4A, NK1, CATHL2, HEP and IDO expression by Q-PCR. The housekeeping $\beta$-ACTIN and GAPDH were selected as housekeeping genes based on previous analyses from our laboratory $[15,16]$ that detected high stability during MSC culture. Realtime PCR primers were designed using PrimerExpress software (Applied Biosystems Incorporated, Foster City, CA, USA; Table 2). Equivalence of amplification efficiencies among all primer-probe sets was confirmed using serial threefold dilutions of BM-MSC and AT-MSC cDNA. Each RT-PCR reaction $(10 \mu \mathrm{L})$ contained the following: 2X Brilliant II SYBR Green QPCR master mix $(5 \mu \mathrm{L})$, target forward primer $(200 \mathrm{nM})$, target reverse primer $(200 \mathrm{nM})$, cDNA synthesis reaction $(1 \mu \mathrm{L})$, and nuclease-free PCR-grade water to adjust final volume. The PCR amplification was carried out in Eco Real-Time PCR System (Illumina Incorporated, San Diego, CA, USA). Thermal cycling conditions were $95^{\circ} \mathrm{C}$ for $10 \mathrm{~min}$, followed by 40 repetitive cycles at $95{ }^{\circ} \mathrm{C}$ for $30 \mathrm{~s}$, and $60{ }^{\circ} \mathrm{C}$ for $1 \mathrm{~min}$. All reactions were performed in triplicate. In each experiment, amount of gene expression was recorded as $\mathrm{CT}$ values that corresponded to the number of cycles where the fluorescence signal can be detected above a threshold value. The CT averages for each biological replicate were calculated and transformed into relative values denominated quantity $(\mathrm{Q})$ through $\Delta \Delta C \mathrm{~T}$ formula [17]. Then, the relative quantification in the expression of target genes for each sample was estimated as the quotient between $\mathrm{Q}$ value of the target gene and a normalization factor (NF), which was calculated based on the geometric mean of housekeeping gene $\mathrm{Q}$ values [17].

\section{Elisa}

The CM, CCM, CACM from activated and non-activated BM-MSC, AT-MSC and FB were collected and centrifuged at $12000 \times g$ for $3 \mathrm{~min}$ at $4{ }^{\circ} \mathrm{C}$. The amounts of

\section{Table 2 Sequence of primers used for Q-PCR analysis}

\begin{tabular}{llc}
\hline Gene & Sense antisense & Accession number \\
\hline Housekeeping genes & & NM_001034034.2 \\
GAPDH & CCTTCATTGACCTTCACTACATGGTCTATGGAAGATGGTGATGGCCTTTCCATTG & NM_173979.3 \\
BACTIN & CGCACCACTGGTATTGTCATTCCAAGGCGACGTAGCAGAG & \\
Antimicrobial peptides genes & & NM_174775.1 \\
bBD4A & GCCAGCATGAGGCTCCATCGGCACAAGAACGGAATACAGA & NM_001046578.1 \\
NK1 & CCAGCAAGAATGTCATCATCCGTCCTTAGAGATGCGATTGAGATAC & NM_174826.3 \\
CATHL2 & GGATTGGTGACGAATCTGGAATGGGCTGGTGAACAGT & NM_001114508.2 \\
HEP & GACAGACGGCACAATGGCACTGGAGGGAGCAGGAATAAATA & NM_001101866.2 \\
IDO & CGAATATACTTGTCTGGTGGGGAGAACATCAAAGCACTG & \\
\hline
\end{tabular}


bBD4A secreted into the medium were measured using an ELISA kit (Cloud-Clone Corporation, Houston TX, USA) according to the manufacturer's instructions.

\section{Data analysis}

Values of percentages of MSC positive for CD73, CD34, Oct-4 and Nanog, $S$. aureus relative growth, bBD4A and NK1 relative expression and bBD4A concentration from three replicates were transferred to a spreadsheet and analyzed using Infostat software. Data was normalized to logarithmic scale in base 10 for normality and mean values for each replicate were compared by one-way ANOVA. Values of $S$. aureus relative growth, bBD4A and NK1 relative expression and bBD4A concentration between treatments and controls were analyzed using Tukey's multiple comparison test $(P<0.05)$.

\section{Results}

Staphylococcus aureus relative growth is reduced in presence of CCM from BM-MSC and AT-MSC derived from bovine fetuses

Isolation of bovine fetal BM-MSC and AT-MSC was performed based on the capacity for plastic attachment under standard culture conditions that included DMEM media supplemented with $10 \%$ FBS. Colonies of fibroblast-like cells attached to the plastic were visualized at Days 5-6 after seeding. BM-MSC exhibited characteristic spindle shape and fibroblast morphology, whereas
AT-MSC displayed subpopulations of polygonal and fibroblast morphology. Mesenchymal CD73, hematopoietic CD34, pluripotent Nanog, and Oct4 markers expressions were determined in BM-MSC and AT-MSC by FACS analysis. A greater $(P<0.001)$ proportion of BMMSC and AT-MSC were positive for CD73 (82.6 $\pm 6.5 \%$ and $79.1 \pm 3.8 \%)$, Nanog $(80.6 \pm 4.7 \%$ and $90.3 \pm 3.1 \%)$, and Oct4 $(93.4 \pm 5.2 \%$ and $91.1 \pm 3.9 \%)$ (Figure 1). Moreover, a lower $(P<0.001)$ proportion of BM-MSC were positive for CD34 (7.6 $\pm 1.2 \%)$ compared to AT-MSC $(9.7 \pm 2.1 \%)$.

The antibacterial capacity of CM from fetal bovine BMMSC and AT-MSC was evaluated under in vitro conditions against a strain SAU-1 of $S$. aureus isolated from a clinical mastitis case. Plain medium (DMEM) was included as a positive control and skin fetal FB were also tested considering its reported potential to secrete AP. After 1, 2 and $3 \mathrm{~h}$ of culture, $S$. aureus relative growth was lower $(P<0.05)$ in CM from FB $(96.4,95.8$, and $95.1 \%)$, BM-MSC (96.1, 95.4, and 94.9\%) and AT-MSC (94.4, 94.2, and $96.1 \%)$ respectively, compared to relative growth in DMEM (124.9, 125, and 126.2\%; Figure 2A). Moreover, $S$. aureus relative growth after 1,2 and $3 \mathrm{~h}$ of culture was lower $(P<0.05)$ in CCM from BM-MSC $(84.9,82.3$, and $80.9 \%)$ and AT-MSC (88.2, 79.8, and 78.8\%) compared to relative growth in concentrated DMEM $(101.7,105.4$, and $114 \%)$ and CCM from FB (106.1, 108.6, and 111.5\%), respectively (Figure $2 \mathrm{~B}$ ).

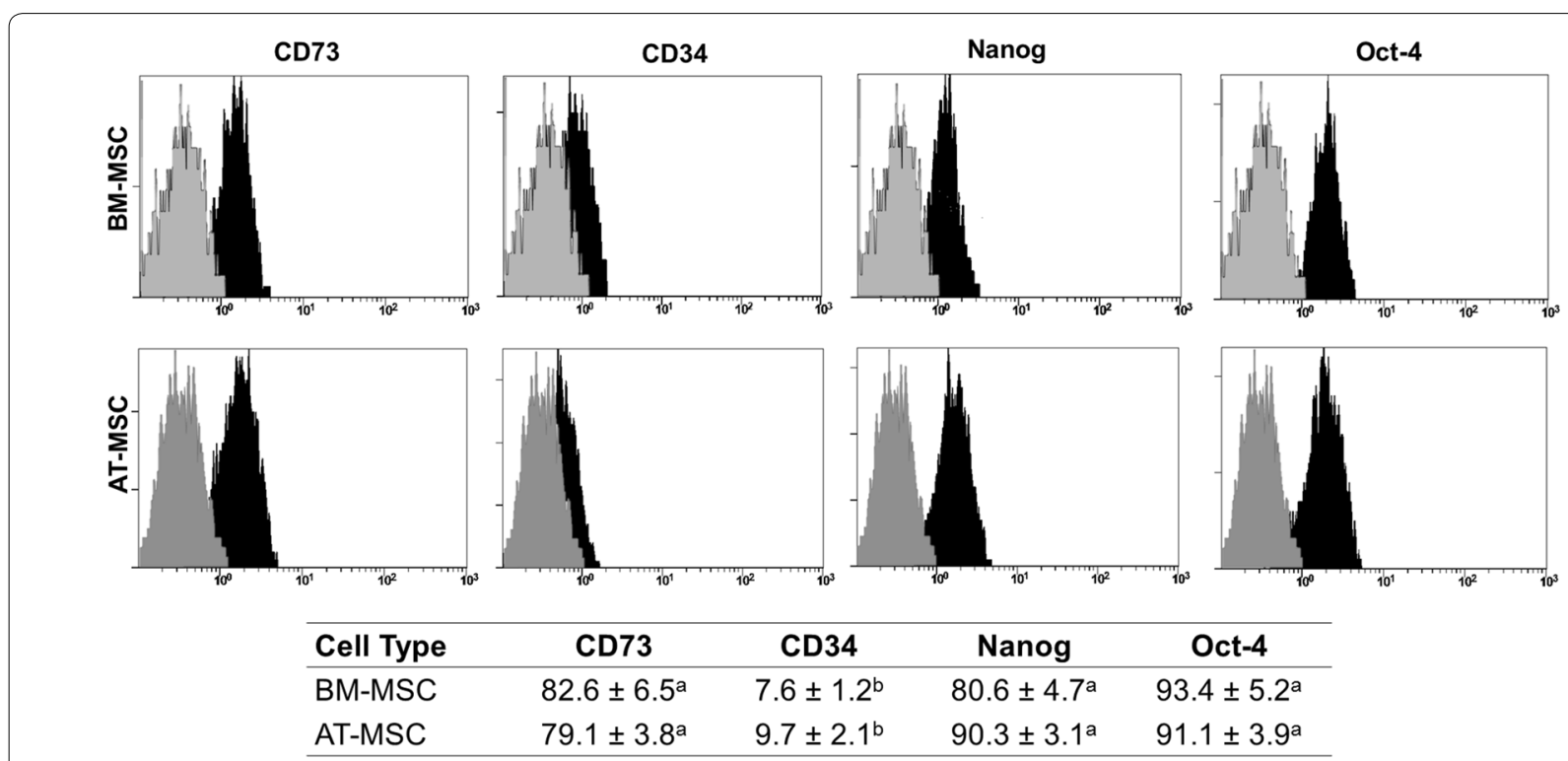

Figure 1 Comparative analysis of expression of mesenchymal CD73, hematopoietic CD34, pluripotent Nanog, and Oct4 markers in bovine fetal BM-MSC and AT-MSC. High proportion of BM-MSC and AT-MSC expressed CD73, Nanog and Oct4. BM-MSC expressed higher levels of CD34 compared to AT-MSC. (a-c) Indicate significant $(P<0.05)$ difference between cell types and marker expression. BM-MSC: Bone marrow-derived mesenchymal stem cells; AT-MSC: adipose tissue-derived mesenchymal stem cells. 
Staphylococcus aureus in vitro relative growth is reduced in presence of activated $\mathrm{CM}$ and activated concentrated CM from BM-MSC and AT-MSC

The direct contact of $S$. aureus and BM-MSC and ATMSC was also evaluated on the antibacterial capacity of ACM from BM-MSC and AT-MSC. After 1, 2 and $3 \mathrm{~h}$ of culture, $S$. aureus relative growth was lower $(P<0.05)$ in ACM from BM-MSC (81.9, 72.9, and 69.9\%) and ATMSC $(83.9,77.5$, and 71.6\%) compared to $S$. aureus relative growth in DMEM (124.9, 124.9, and 126.2\%), CM from FB (96.4, 95.8, and 95.1\%), ACM from FB (94.1, 93.6, and 92.6\%), CM from BM-MSC (96.1, 95.4, and 94.9\%) and CM from AT-MSC (94.4, 94.2, and 96.1\%), respectively (Figure 3A). Similarly, S. aureus relative growth after 1,2 and $3 \mathrm{~h}$ of culture was reduced $(P<0.05)$ in CACM from BM-MSC (82, 79.3, and 70.9\%) and AT-MSC (86.2, 79.3, and 69.3\%) compared to bacterial growth in DMEM (103.1, 106, and 107.7\%), CCM from FB (102.4, 102.4, and 105.7\%), CACM from FB (95.7, 95.1, and 97.3\%), CCM from BM-MSC (95.7, 93.1, and 93.2\%),

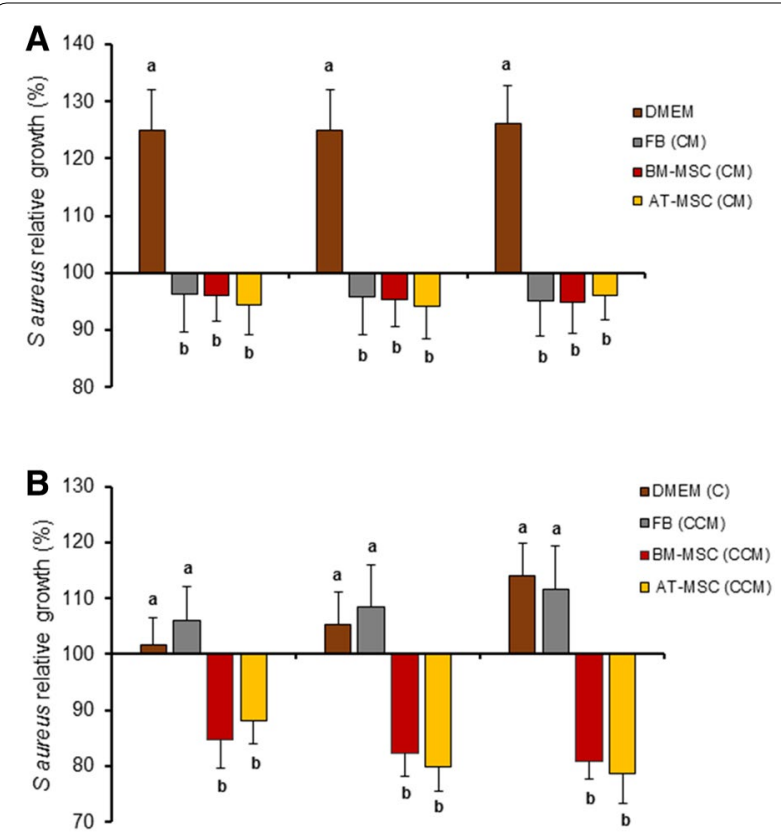

Figure 2 Relative growth of $S$. aureus after 1,2 and $3 \mathrm{~h}$ of incubation in CM and CCM from bovine fetal $F B, B M-M S C$ and AT-MSC. A S. aureus relative growth was lower $(P<0.05)$ in $C M$ from FB, BM-MSC, and AT-MSC compared to relative growth in DMEM (positive control). B S. aureus relative growth after 1, 2 and $3 \mathrm{~h}$ of culture was lower $(P<0.05)$ in CCM from BM-MSC and AT-MSC compared to growth in concentrated DMEM and CCM from FB, respectively. $(a, b)$ Indicate significant $(P<0.05)$ difference between cell type and DMEM. DMEM: Dulbecco's Modified Eagle Medium; FB: fibroblasts, BM-MSC: bone marrow-derived mesenchymal stem cells; AT-MSC: adipose tissue-derived mesenchymal stem cells; CM: conditioned media; CCM: concentrated conditioned media.

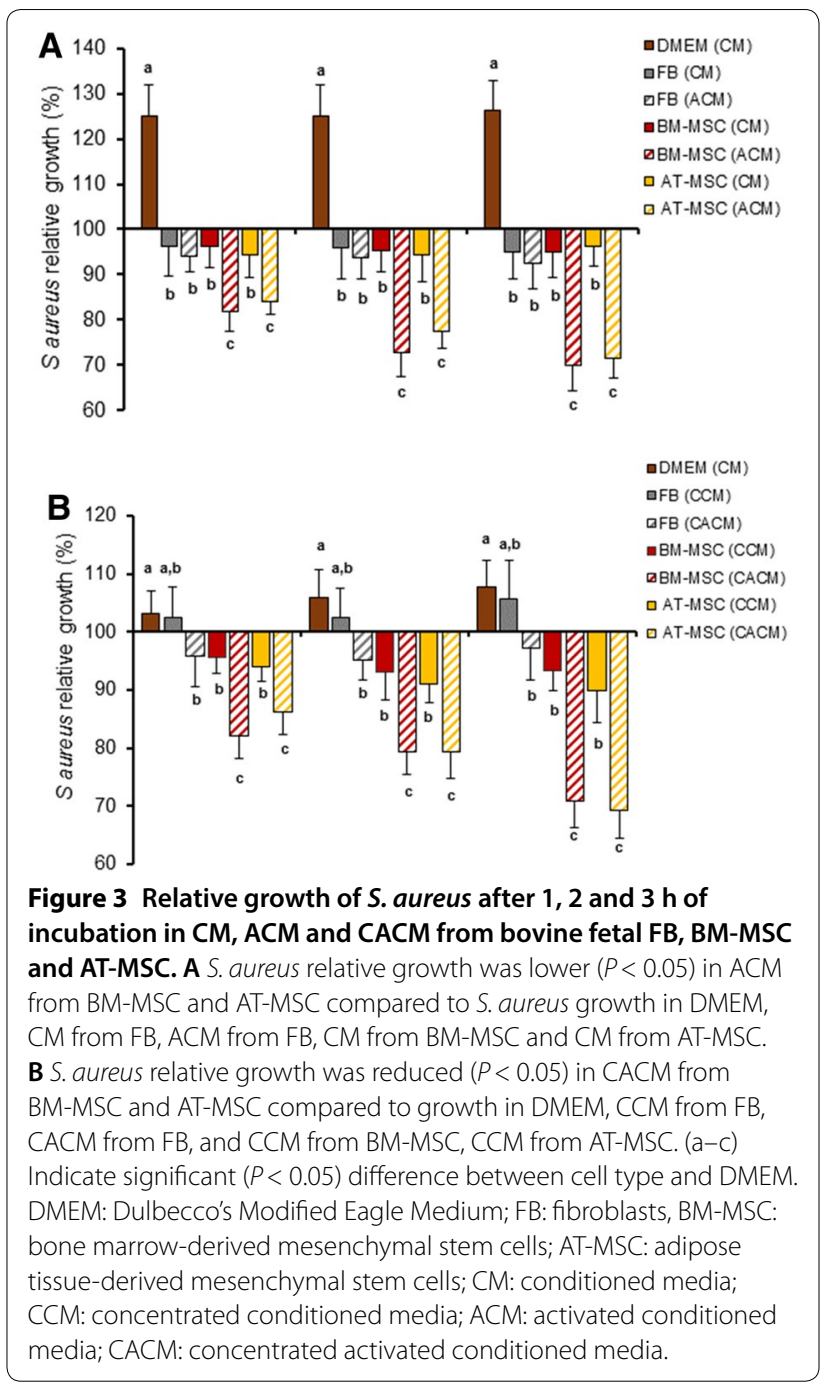

CCM from AT-MSC (94.1, 91, and 89.9\%), respectively (Figure 3B).

\section{Direct contact with $S$. aureus increases bBD4A and NK1} expression in BM-MSC, AT-MSC and FB from bovine fetuses Levels of mRNA of bBD4A, NK1, CATHL2, HEP and IDO were evaluated in fetal bovine BM-MSC, AT-MSC and $\mathrm{FB}$ cultures after direct contact with $S$. aureus (activated MSC). Moreover, concentrations of bBD4A were quantified in $\mathrm{CM}, \mathrm{ACM}$ and $\mathrm{CACM}$ from fetal bovine BM-MSC, AT-MSC and FB. Levels of mRNA of CATHL2, HAMP and IDO were not detected in non-activated or activated MSC. bBD4A mRNA levels increased $(P<0.05) 1.2$ - and 3.5 -fold in activated BMMSC and AT-MSC compared to non-activated controls (Figure 4A). No significant differences in bBD4A mRNA levels were detected between activated and non-activated 

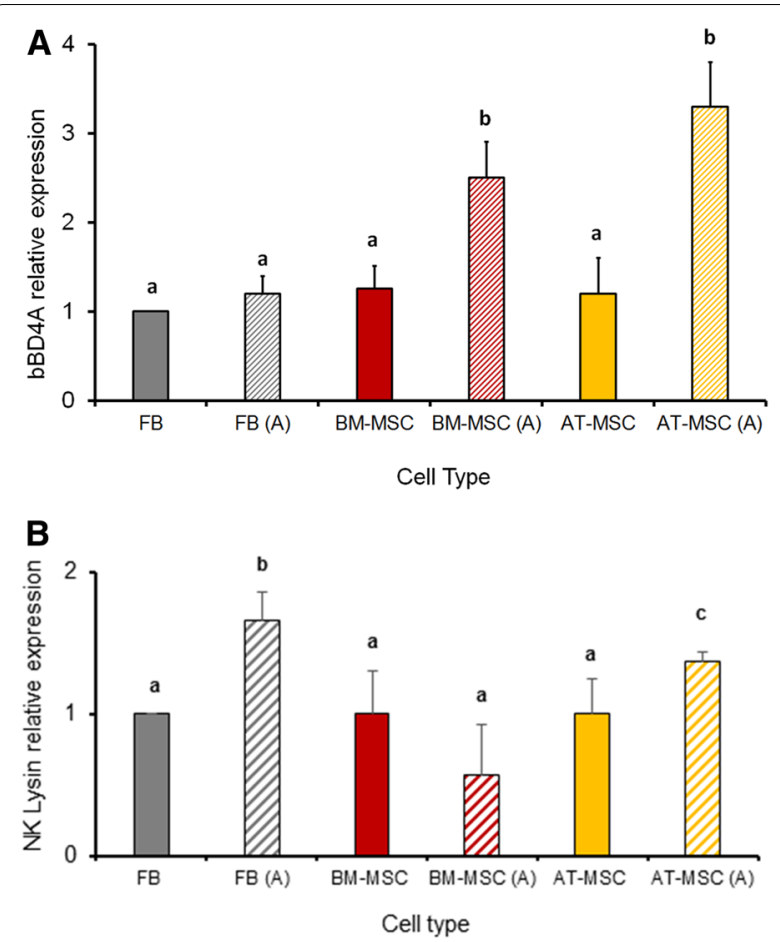

Figure 4 Analysis of antibacterial related molecules mRNA levels in bovine fetal FB, BM-MSC and AT-MSC activated by exposure to $\mathbf{S}$. aureus for $\mathbf{6}$ h. A bBD4A mRNA levels increased $(P<0.05)$ in activated BM-MSC and AT-MSC compared to non-activated controls. B NK1 mRNA levels increased $(P<0.05)$ in activated FB and AT-MSC compared to non-activated controls. (a-C) Indicate significant $(P<0.05)$ difference between activated and no-activated cell type. FB: Fibroblasts, BM-MSC: bone marrow-derived mesenchymal stem cells; AT-MSC: adipose tissue-derived mesenchymal stem cells; A: activated.

FB. NK1 mRNA levels increased $(P<0.05) 1.4$ - and 1.7fold in activated FB and AT-MSC compared to non-activated controls (Figure 4B). Filtration increased bBD4A concentration in CCM from FB, BM-MSC and AT-MSC (37.3, 36.4 and $34.5 \mathrm{pg} / \mathrm{mL}$ ) compared to $\mathrm{CM}(8.1,23.4$, $12.7 \mathrm{pg} / \mathrm{mL}$, respectively; Figure $5 \mathrm{~A})$. Activation of BMMSC and AT-MSC increased $(P>0.05)$ bBD4A levels in ACM compared to CM (29.4 vs. 16 and 11.7 vs. $5.8 \mathrm{pg} /$ $\mathrm{mL}$, respectively; Figure $5 \mathrm{~B})$. Moreover, $\mathrm{CACM}$ had higher $(P<0.05)$ bBD4A levels in BM-MSC and ATMSC (39.6 and $27.6 \mathrm{pg} / \mathrm{mL}$ ) compared to ACM (28.1 and $19.9 \mathrm{pg} / \mathrm{mL})$.

\section{Discussion}

To our knowledge, this study is the first reported comparative analyses of bovine fetal BM-MSC and AT-MSC based on antibacterial potentials against mastitis-causing pathogen $S$. aureus. Moreover, this study describes an association between the expression of AP genes
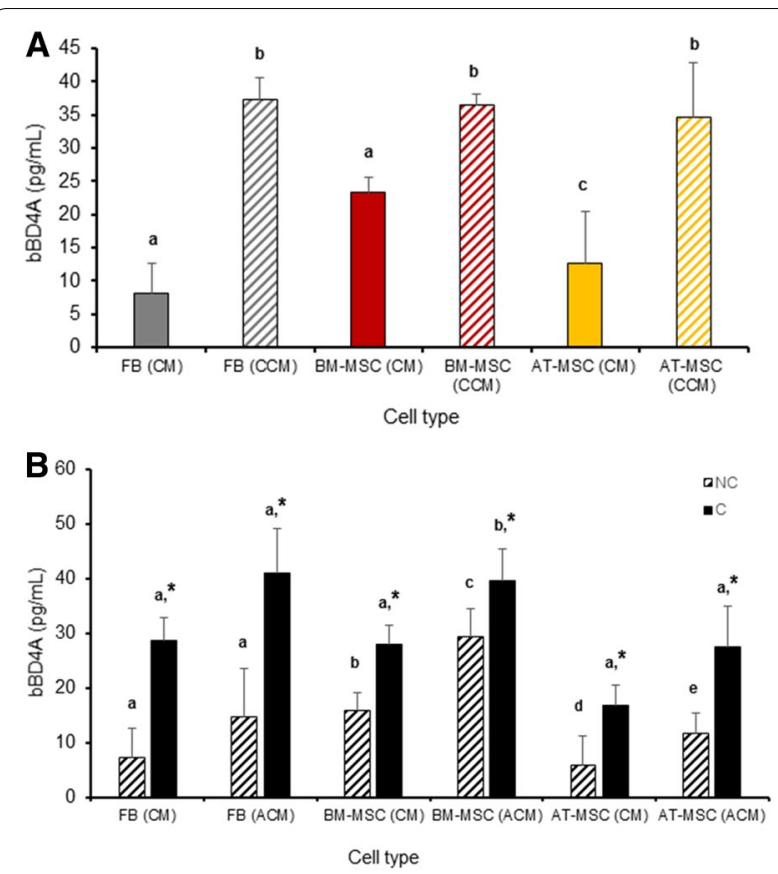

Figure 5 Analysis of bBD4A protein levels in CM, ACM and CACM from bovine fetal FB, BM-MSC and AT-MSC bovine fetal FB, BM-MSC and AT-MSC activated by exposure to $S$. aureus for $\mathbf{6} \mathbf{h}$. Higher levels of bBD4A were detected in CCM from FB, BM-MSC and AT-MSC compared to CM. Activation of BM-MSC and AT-MSC increased $(P>0.05)$ bBD4A levels in ACM compared to CM. Moreover, CACM had higher $(P<0.05)$ bBD4A levels in BM-MSC and AT-MSC compared to ACM. (a-d) Indicate significant $(P<0.05)$ difference between $C M$ and $C C M(\mathbf{A})$ and $C M$ and $A C M(B)$ from each cell type. $\left(^{*}\right)$ Indicate significant $(P<0.05)$ difference between CM and CCM from each cell treatment. FB: Fibroblasts, BM-MSC: bone marrow-derived mesenchymal stem cells; AT-MSC: adipose tissue-derived mesenchymal stem cells; CM: conditioned media; CCM: concentrated conditioned media; ACM: activated conditioned media; NC: non-concentrated; C: concentrated.

bBD4A and NK1 and bBD4A protein and the antibacterial capacity of BM-MSC and AT-MSC. The majority of plastic-adherent populations of BM-MSC and AT-MSC expressed mesenchymal marker CD73 and were negative for hematopoietic marker CD34, indicating that the isolated cell populations exhibited specific profile of MSC [3]. Although, bovine fetal BM-MSC and AT-MSC displayed similar patterns of expression of CD73 and CD34, previous studies have reported lower expression of CD34 in canine, equine and human MSC [18-20]. In this regard, expression of CD34 may be associated to the extension of culture period since freshly isolated MSC express low levels of CD34 but extended cultured MSC lack expression of this protein [21]. Moreover, BM-MSC and AT-MSC expressed similar levels of pluripotent transcriptional factors Nanog and Oct4, suggesting features of multipotent cells. 
Despite the antibacterial mechanism of MSC during bacterial exposure has not been completely elucidated, it has been reported that MSC alter their secreted products, migration, proliferation and differentiation upon encounter with bacteria [22]. In the case of S. aureus, exposure of human MSC to this pathogen increases production of several paracrine factors including VEGF, SDF-1, and IL-6, that are involved in the influx and activation of inflammatory cells to infected tissue [23]. In vivo experiments indicate that treatment with MSC reduce bacterial infection and inflammatory response in rats infected with methicillin-resistant S. aureus [24]. Bacterial clearance in vivo may be associated in part to phagocytosis since sepsis-induced mice treated with MSC reduce inflammation (IL-10 and IL-6) while enhancing phagocytosis of $S$. aureus [25].

Despite reports on immunomodulatory and phagocytic activity of MSC, the antibacterial response against $S$. aureus may be primarily driven by production of AP. These peptides are part of the innate immunity that provides the first line of defense against pathogenic microorganisms [26]. In the present study, the expression of five AP was evaluated, and the expression of bBD4A and NK1 was present and associated to the in vitro antibacterial effect of MSC. bBD4A expression in BM-MSC and AT-MSC, and the antibacterial capacity of their CM was increase after exposure for $6 \mathrm{~h}$ with $S$. aureus. In contrast, FB used as negative controls but did not showed upregulation in BD4A mRNA levels or protein expression after exposure to $S$. aureus. In addition, CM from FB did not reduce $S$. aureus proliferation, which suggest that $\mathrm{BD} 4 \mathrm{~A}$ may be the main AP responsible for the inhibitory effect of CM from BM-MSC and AT-MSC against this pathogen.

In contrast to bBD4A and NK1, the expression of two previously reported MSC-derived AP, CATHL2 and HEP was not detected in BM-MSC or AT-MSC. These results provide evidence on the potential role of selected AP including bBD4A and NK1in the reduction of S. aureus growth under in vitro conditions. Defensins constitute a large family of small, cysteine rich, cationic peptides that have been found in various tissues in many animal species and are capable of killing a broad spectrum of pathogens [27]. The lingual antimicrobial peptide (LAP), one of the first characterized bovine $\beta$-Defensins, was isolated from swollen tongue of cattle [28]. It has been reported that $\beta$-Defensins are present in the cow milk [29] and exhibit antibacterial capacity against $S$. aureus [30]. A positive relationship has been found between somatic cell count (SCC) in milk and LAP mRNA expression, which was localized in epithelial cells of cow mastitic tissue [31]. Moreover, LAP concentration and SCC in milk are also increased after intramammary administration of lipopolysaccharide (LPS) in cows or heat-killed S. aureus in goats [32-34]. Overall these results indicate that secretion of $\beta$-Defensins is stimulated by $S$. aureus not only in epithelial cells of the mammary gland but also in BMMSC and AT-MSC derived from bovine fetuses.

Exposure to $S$. aureus augmented mRNA levels of NK1 in AT-MSC but not in BM-MSC. These results suggest that antibacterial strategy against $S$. aureus variates depending on MSC tissue sources. NK1 is a cationic AP firstly isolated from porcine small intestine that is produced by cytotoxic T and NK cells [35]. In the bovine, four NK-lysin genes have been described (NK1, NK2A, NK2B and NK2C) with higher expression in the Peyer's patch (NK1, NK2A and NK2B) and the lung (NK2C) [36]. All four synthetic forms of NK-lysin peptides had antibacterial capacity against S. aureus [36]. Recently, genetics variants within the bovine NK-lysin gene have been reported which potentially provides two candidate genetic markers for association with health-related phenotypes [36].

Indolamine 2,3-dioxygenase, CATHL2 and HEP mRNA levels were not detected in the experiments using bovine fetal MSC. Previous studies have indicated that human MSC require the effect of inflammatory signals such as IFN $\gamma$ and TNF $\alpha$, in order to activate expression of IDO [6]. This study also reported antibacterial activity of IDO against of $S$ aureus. Conversely, mice MSC lacking expression of IDO do not inhibit $S$. aureus growth [6]. Similarly, in previous in vitro experiments we found that IFN $\gamma$ treatment induced activation of IDO mRNA expression in bovine fetal MSC and that IDO mRNA levels have a dose-response effect with IFNY concentration (unpublished data). These studies indicate that exposure to an inflammatory environment is required for MSC in order to express IDO and that this factor is not the exclusive antibacterial factor against $S$. aureus. CATHL2 is another AP that is produced by human and equine MSC and has been involved in the antibacterial capacity of MSC against S. aureus [37, 38]. CATHL2 is synthesized by bovine mammary epithelial cells and is up-regulated in response to S. aureus [39]. Similarly, HAMP activity has also been associated to $S$. aureus inhibition [40] and its expression has been reported in menstrual-derived MSC [7]. The lack of expression of CATHL2 and HEP in bovine fetal MSC after exposure to $S$. aureus may be associated to a tissue-specific localization and regulation of these peptides; however, further analyses may be required in order to determine the potential participation of these factors after exposure to different pathogens.

Our data indicate that $\mathrm{CM}$ from fetal bovine BMMSC and AT-MSC has the capacity to reduce in average $\sim 30 \%$ of $S$. aureus relative growth under in vitro conditions. Moreover, concentration by filtration 
and pre-exposure to $S$. aureus increased antibacterial capacity of CM against $S$. aureus. From four AP evaluated, expression of two of them, bBD4A and NK1 was present and associated to the in vitro antibacterial effect of MSC.

\section{Abbreviations}

BM-MSC: bone marrow-derived mesenchymal stem cells; AT-MSC: adipose tissue-derived mesenchymal stem cells; FB: fibroblasts; CM: conditioned media; CCM: concentrated conditioned media; ACM: activated conditioned media; CACM: concentrated activated conditioned media; DMEM: Dulbecco's Modified Eagle medium; FBS: fetal bovine serum; PBS: phosphate-buffered saline; AP: antibacterial peptides; bBD-4A: $\beta$-defensin 4A; NK1: NK-lysine 1; CATHL2: cathelicidin 2; HEP: hepcidin; IDO: indoleamine 2,3 dioxygenase; FBS: fetal bovine serum; FACS: fluorescence-activated cell sorter; Q-PCR: quantitativepolymerase chain reaction.

\section{Competing interests}

The authors declare that they have no competing interests.

\section{Authors' contributions}

The authors responsibilities were as follows: $\mathrm{BC}, \mathrm{OH}, \mathrm{MJ}$ and JB performed cell isolation and culture expansion. BC and PR performed S. aureus culture, antimicrobial assays, statistical analyses and helped in the manuscript drafting. JB, JC, JP and AE participated in the FACS, Q-PCR and ELISA analyses. OAP and CGT obtained financial support, conceived and designed the study, analyzed the data and drafted the manuscript. All authors read and approved the final manuscript.

\section{Acknowledgements}

We acknowledge Dr Leonardo Saenz from the Veterinary School of University of Chile for providing the SAU-1S strain of S. aureus. We also thank Dr Monica De los Reyes from the Veterinary School of University of Chile for their technical assistance in the flow cytometric analyses.

\section{Author details}

${ }^{1}$ Department of Animal Production Science, Faculty of Veterinary Medicine, University of Chile, 8820808 Santiago, Chile. ${ }^{2}$ Institute of Dental Science Research, Faculty of Dentistry, University of Chile, 8380492 Santiago, Chile. ${ }^{3}$ Department of Preventive Medicine, Faculty of Veterinary Medicine, University of Chile, 8820808 Santiago, Chile. ${ }^{4}$ Department of Clinical Sciences, Faculty of Veterinary Medicine, University of Chile, 8820808 Santiago, Chile. ${ }^{5}$ Department of Biomedical Sciences and Pathobiology, Virginia-Maryland Regional College of Veterinary Medicine, Virginia Tech, Blacksburg, VA 24060, USA. ${ }^{6}$ Present Address: Institute of Pharmacology and Morphophysiology, Faculty of Veterinary Sciences, Austral University of Chile, 5110566 Valdivia, Chile.

\section{Availability of data and materials}

All data generated or analyzed during this study are included in this article and the additional files.

\section{Consent for publication}

Not applicable.

\section{Ethics approval and consent to participate}

All procedures have been approved by the Bioethical Committee of the Scientific and Technological Development Support Fund (FONDEF) Grant ID15I10129, Government of Chile.

\section{Funding}

This study was supported by Grant ID15110129 from the Scientific and Technological Development Support Fund (FONDEF) from the Ministry of Education, Government of Chile. The scholarships of Drs. Berly Cahuascanco and Olger Huaman were funded by the National Program for Scholarships (PRONABEC) from the Government of Perú.

\section{Publisher's Note}

Springer Nature remains neutral with regard to jurisdictional claims in published maps and institutional affiliations.

Received: 28 January 2019 Accepted: 24 March 2019

Published online: 11 April 2019

\section{References}

1. Pittenger MF, Mackay AM, Beck SC, Jaiswal RK, Douglas R, Mosca JD, Moorman MA, Simonetti DW, Craig S, Marshak DR (1999) Multilineage potential of adult human mesenchymal stem cells. Science 284:143-147

2. Harichandan A, Bühring MJ (2011) Prospective isolation of human MSC. Best Pract Res Clin Haematol 24:25-36

3. Dominici M, Le Blanc K, Mueller I, Slaper-Cortenbach I, Marini FC, Krause DS, Deans RJ, Keating A, Prockop DJ, Horwitz EM (2006) Minimal criteria for defining multipotent mesenchymal stromal cells. The International Society for Cellular Therapy position statement. Cytotherapy 8:315-317

4. Caplan Al, Correa D (2011) The MSC: an injury drugstore. Cell Stem Cell 9:11-15

5. Krasnodembskaya A, Song Y, Fang X, Gupta N, Serikov V, Lee J-L, Matthay MA (2010) Antibacterial effect of human mesenchymal stem cells is mediated in part from secretion of the antimicrobial peptide LL-37. Stem Cells 28:2229-2238

6. Meisel R, Brockers S, Heseler K, Degistirici O, Bülle H, Woite C, Stuhlsatz S, Schwippert W, Jäger M, Sorg R, Henschler R, Seissler J, Dilloo D, Däubener W (2011) Human but not murine multipotent mesenchymal stromal cells exhibit broad-spectrum anti-microbial effector function mediated by indoleamine 2,3-dioxygenase. Leukemia 25:648-654

7. Alcayaga-Miranda F, Cuenca J, Martin A, Contreras L, Figueroa FE, Khoury M (2015) Combination therapy of menstrual derived mesenchymal stem cells and antibiotics ameliorates survival in sepsis. Stem Cell Res Ther 6:199

8. Lombardi L, Maisetta G, Batoni G, Tavanti A (2015) Insights into the antimicrobial properties of hepcidins: advantages and drawbacks as potential therapeutic agents. Molecules 20:6319-6341

9. Reyher KK, Dufour S, Barkema HW, Des Côteaux L, Devries TJ, Dohoo IR, Keefe GP, Roy JP, Scholl DT (2011) The National Cohort of Dairy Farms: a data collection platform for mastitis research in Canada. J Dairy Sci 94:1616-1626

10. Keefe G (2012) Update on control of Staphylococcus aureus and Streptococcus agalactiae for management of mastitis. Vet Clin North Am Food Anim Pract 28:203-216

11. Makovec JA, Ruegg PL (2003) Antimicrobial resistance of bacteria isolated from dairy cow milk samples submitted for bacterial culture: 8905 samples (1994-2001). J Am Vet Med Assoc 222:1582-1589

12. Gomes F, Henriques M (2016) Control of bovine mastitis: old and recent therapeutic approaches. Curr Microbiol 72:377-382

13. Farm Animal Welfare Council (2009) Opinion on the welfare of the dairy cow. https://assets.publishing.service.gov.uk/government/uploads/syste m/uploads/attachment_data/file/325044/FAWC_opinion_on_dairy _cow_welfare.pdf. Accessed 12 Dec 2018

14. De Oliveira AP, Watts JL, Salmon SL, Aarestrup FM (2000) Antimicrobial susceptibility of Staphylococcus aureus isolated from bovine mastitis in Europe and the United States. J Dairy Sci 83:855-862

15. Cortes Y, Ojeda M, Araya D, Dueñas F, Fernández MS, Peralta OA (2013) Isolation and multilineage differentiation of bone marrow mesenchymal stem cells from abattoir-derived bovine fetuses. BMC Vet Res 9:133

16. Dueñas F, Becerra V, Cortes Y, Vidal S, Saenz L, Palomino J, De Los Reyes M, Peralta OA (2014) Hepatogenic and neurogenic differentiation of bone marrow mesenchymal stem cells from abattoir-derived bovine fetuses. BMC Vet Res 10:154

17. Vandosempele J, De Preter K, Pattyn F, Poppe B, Van Roy N, De Paepe A, Speleman F (2002) Accurate normalization of real-time quantitative RT-PCR data by geometric averaging of multiple internal control genes. Genome Biol 3:RESEARCH0034

18. Takemitsu H, Zhao D, Yamamoto I, Harada Y, Michishita M, Arai T (2012) Comparison of bone marrow and adipose tissue-derived canine mesenchymal stem cells. BMC Vet Res 8:150 
19. Ranera B, Lyahyai J, Romero A, Vazquez FJ, Remacha AR, Bernal ML, Zaragoza P, Rodellar C, Martin-Burriel I (2011) Immunophenotype and gene expression profiles of cell Surface markers of mesenchymal stem cells derived from equine bone marrow and adipose tissue. Vet Immunol Immunopathol 144:147-154

20. Strioga M, Viswanathan S, Darinskas A, Slaby O, Michalek J (2012) Same or not the same? Comparison of adipose tissue-derived versus bone marrow-derived mesenchymal stem stromal cells. Stem Cells Dev 21:2724-2752

21. Lin CS, Ning H, Lin G, Lue TF (2012) Is CD34 truly a negative marker for mesenchymal stromal cells? Cytotherapy 14:1159-1163

22. Mezey E, Nemeth K (2015) Mesenchymal stem cells and infectious diseases: smarter that drugs. Immunol Lett 168:208-214

23. Ward CL, Sanchez CJ Jr, Pollot BE, Romano DR, Hardy SK, Becerra SC, Rathbone CR, Wenke JC (2015) Soluble factors from biofilms of wound pathogens modulate human bone marrow-derived stromal cell differentiation, migration, angiogenesis, and cytokine secretion. BMC Microbiol 15:75

24. Yuan Y, Lin S, Guo N, Zhao C, Shen S, Bu X, Haiqing Y (2014) Marrow mesenchymal stromal cells reduce methicillin-resistant Staphylococcus aureus infection in rat models. Cytotherapy 16:56-63

25. Mei SH, Haitsma JJ, Dos Santos CC, Deng Y, Lai PFH, Slutsky AS, Liles WC, Stewart D (2010) Mesenchymal stem cells reduce inflammation while enhancing bacterial clearance and improving survival in sepsis. Am J Respir Crit Care Med 182:1047-1057

26. Zasloff M (2002) Antimicrobial peptides of multicellular organisms. Nature 415:389-395

27. Selsted ME, Ouellette AJ (2005) Mammalian defensins in the antimicrobial immune response. Nat Immunol 6:551-557

28. Schonwetter BS, Stolzenberg ED, Zasloff MA (1995) Epithelial antibiotics induced at sites of inflammation. Science 267:1645-1648

29. Isobe N, Nakamura J, Nakano H, Yoshimura Y (2009) Existence of functional lingual antimicrobial peptide in bovine milk. J Dairy Sci 92:2691-2695

30. Taha-Abdelaziz K, Perez-Casal J, Schott C, Hsiao J, Attah-Poku S, Slavic D, Caswell JL (2013) Bactericidal activity of tracheal antimicrobial peptide against respiratory pathogens of cattle. Vet Immunol Immunopathol 152:289-294
31. Swanson K, Gorodetsky S, Good L, Davis S, Musgrave D, Stelwagen K, Farr V, Molenaar A (2004) Expression of a b-defensin mRNA, lingual antimicrobial peptide, in bovine mammary epithelial tissue is induced by mastitis. Infect Immun 72:7311-7314

32. Morimoto K, Kanda N, Shinde S, Isobe N (2012) Effect of enterotoxigenic Escherichia coli vaccine on innate immune function of bovine mammary gland infused with lipopolysaccharide. J Dairy Sci 95:5067-5074

33. Kawai K, Korematsu K, Akiyama K, Okita M, Yoshimura Y, Isobe N (2015) Dynamics of lingual antimicrobial peptide, lactoferrin concentrations and lacto peroxidase activity in the milk of cows treated for clinical mastitis. Anim Sci J 86:153-158

34. Kuwahara K, Yoshimura Y, Isobe N (2017) Effect of steroid hormones on the innate immune response induced by Staphylococcus aureus in the goat mammary gland. Reprod Domest Anim 52:579-584

35. Andersson M, Gunne H, Agerberth B, Boman A, Bergman T, Sillard R, Jörnvall H, Mutt MV, Olsson B, Wigzell H, Dagerlind A, Boman HG, Gudmundsson GH (1995) NK-lysin, a novel effector peptide of cytotoxic T and NK cells. Structure and cDNA cloning of the porcine form, induction by interleukin 2, antibacterial and antitumour activity. EMBO J 14:1615-1625

36. Chen J, Lee MO, Womack JE (2017) Genetic variation and gene conversions within the bovine NK-lysin gene family. Anim Genet 48:225-227

37. Sutton MT, Fletcher D, Ghosh SK, Weinberg A, van Heeckeren R, Kaur S, Sadeghi Z, Hijaz A, Reese J, Lazarus HM, Lennon DP, Caplan Al, Bonfield TL (2016) Antimicrobial properties of mesenchymal stem cells: therapeutic potential for cystic fibrosis infection, and treatment. Stem Cells Int 2016:5303048

38. Harman M, Yang S, He MK, Van de Walle GR (2017) Antimicrobial peptides secreted by equine mesenchymal stromal cells inhibit the growth of bacteria commonly found in skin wounds. Stem Cell Res Ther 8:157

39. Ibeagha-Awemu EM, Ibeagha AE, Messier S, Zhao X (2010) Proteomics, genomics, and pathway analyses of Escherichia coli and Staphylococcus aureus infected milk whey reveal molecular pathways and networks involved in mastitis. J Proteome Res 9:4604-4619

40. Park CH, Valore EV, Waring AJ, Ganz T (2001) Hepcidin, a urinary antimicrobial peptide synthesized in the liver. J Biol Chem 276:7806-7810
Ready to submit your research? Choose BMC and benefit from:

- fast, convenient online submission

- thorough peer review by experienced researchers in your field

- rapid publication on acceptance

- support for research data, including large and complex data types

- gold Open Access which fosters wider collaboration and increased citations

- maximum visibility for your research: over $100 \mathrm{M}$ website views per year

At BMC, research is always in progress.

Learn more biomedcentral.com/submissions 